\title{
A STUDY OF THE HUMAN MYOGRAM. A STUDY OF NORMALS, AND OF PATIENTS WITH ADDISON'S DISEASE, THYROTOXI- COSIS AND PROGRESSIVE MUSCULAR ATROPHY ${ }^{1}$
}

\author{
By ROY L. SWANK AND GRACE E. BERGNER 2 \\ (From the Medical Clinics, Peter Bent Brigham Hospital, Neurological Unit, Boston City Hos- \\ pital, and Neurological and Medical Departments, Harvard Medical School, Boston)
}

(Received for publication July 25, 1947)

A simple method of myography is often needed in the clinic to confirm one's impression of impaired or normal muscle function. The method. should not depend upon the patient's voluntary performance, and should not be so painful that repeated testing is objected to by the patient. In the present study a method of myography similar to that used in animal experiments has been employed. Without anesthesia the ulnar nerve was electrically stimulated at the elbow by means of skin electrodes. The maximum contractions of the muscles in the forearm and hand innervated by the ulnar nerve (flexor carpi ulnaris; ulnar head of flexor digitorum profundus; and intrinsic muscles of the hand) were measured mechanically by an isotonic myograph and recorded on a slowly moving paper by an ink writer.

Because of the pain and consequent variability of the muscular contractions which attended high frequency stimulation of the ulnar nerve, the present method utilized stimulation frequencies varying from once every 10 seconds to 8 per second. Even at these slower frequencies pain was frequently sufficiently severe to render the muscle curves of little use. In approximately half of the subjects, however, reliable myographic tracings were obtainable and, in each of these tests, the curves for the same individual were practically identical on repeated tests.

\section{METHOD}

The subject was seated comfortably and the right or left forearm was fitted firmly without constriction into a rigid supporting frame (Figure 1). The elbow was flexed at a right angle and the forearm was semipronated. To allow freedom of movement, the wrist

1 This study was aided in part by a grant from the Committee on Research in Endocrinology, National Research Council.

2 Commonwealth Fund Fellow, 1945-1947. extended beyond the end of the frame. A leather strap around the hand was connected to the myograph by a cord over a pulley. The tension of the myograph was varied by elastic bands of different stiffness which required weights of approximately 300 to 1000 grams to produce a deflection of the myograph equal to a single muscular twitch. The stimulating electrode was a wedgeshaped piece of solder about $2 \mathrm{~cm}$. long. It was grooved for electrode paste. The electrode was securely taped over the ulnar nerve where it lies between the medial condyle of the humerus and the olecranon. The electrode was usually placed in the inferior part of the fossa as distant as possible from the sensory nerves which emerge superiorly. The indifferent electrode was a piece of copper screening 7.5 by $15 \mathrm{~cm}$. covered by cheese cloth and soaked in salt solution. It was placed on the opposite arm. The stimuli consisted of monophasic square wave discharges of one millisecond duration produced by a Grass stimulator. ${ }^{3}$ Stimuli of longer duration were too painful while stimuli of shorter duration did not give consistent optimal responses. The strength of stimulation varied with the individual and ranged from 20 to 65 volts. It was relatively constant for the same person on repeated tests.

The following routine was finally adopted for test purposes. At the beginning of each experiment, stimuli were delivered every 10 seconds, until the voltage giving the maximum mechanical response was found. Suboptimal mechanical responses were produced by excessively strong as well as by submaximal stimuli. In the former instance it was due to spread of the current to antagonistic muscles and to apprehensive fixation of the wrist and forearm by the subject incident to the pain of strong electrical stimulation. After selection of the optimal voltage the ulnar nerve was stimulated once every 2 seconds for $11 / 2$ minutes. This test period was followed by a rest period during which stimuli were delivered every 10 seconds. This continued until the potentiation resulting from the test run had disappeared and the height of contractions had returned to their former level. The rate of stimulation was increased to $1,2,4,8$, and occasionally 16 per second during succeeding test runs, usually of $11 / 2$ minutes' duration. Between these periods of rapid stimulation shocks were given every 10 seconds until the height of contraction fell to a constant level.

3 This instrument was supplied to us by the Grass Instrument Co., Quincy, Mass. 


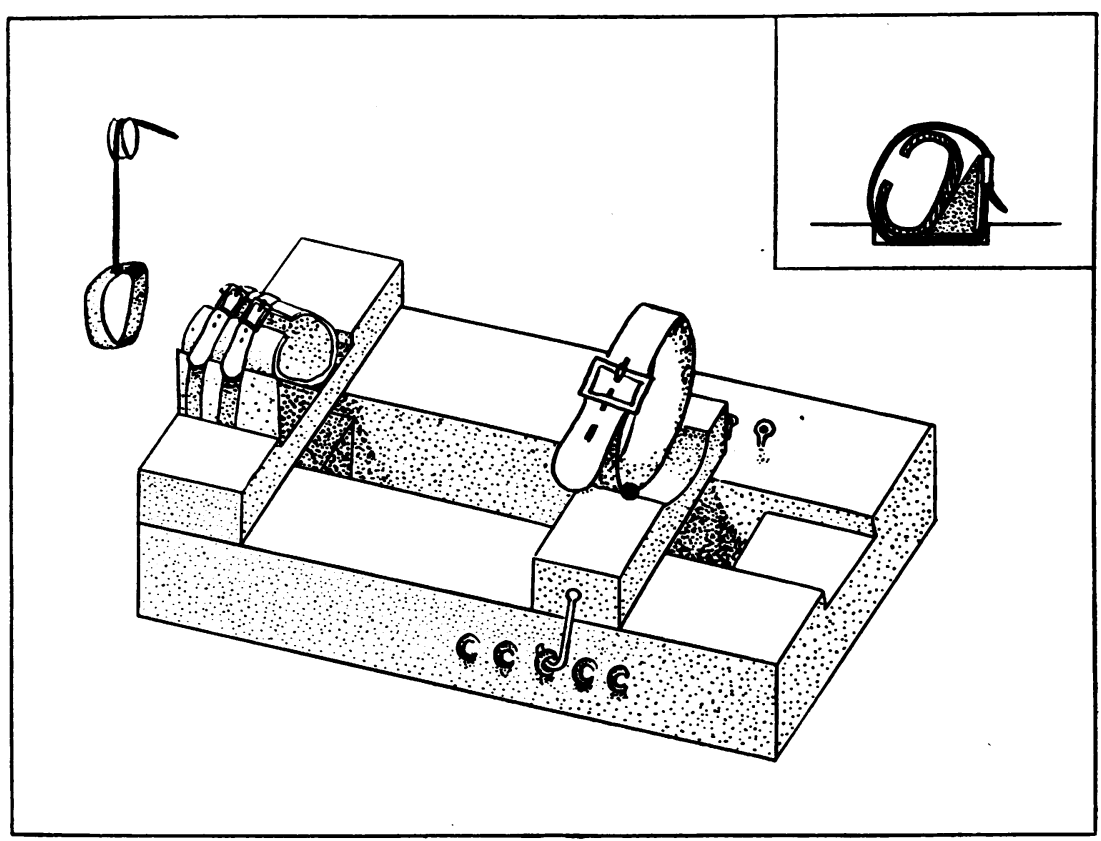

Fig. 1. A Draining of the Arm Holder

The single wide strap at the right fits loosely around the forearm just below the elbow. The 2 narrow straps to the left secure the wrist, the head of the radius being held firmly against the upper end of the angulated block of wood shown in cross-section. The wrist is wrapped by a layer of felt about $1 / 8$ inch thick to protect it from the wooden block. Three angulated wood blocks were available, one $60^{\circ}$, one $45^{\circ}$, and the other $30^{\circ}$ from the horizontal. The one shown in the insert (approximately $60^{\circ}$ ) usually gave the best responses. The leather loop to the left of the wrist holder fits around the hand which is held slightly extended. A cord extends from this leather loop over a pulley to the myograph which records horizontally, by an ink writer 5 inches long, on slowly moving paper.

\section{RESULTS}

\section{Obscrvations on normal subjects.}

The strength of a single muscular contraction seemed to correlate with the general muscular strength of the subjects being tested. Figures $2 \mathrm{~A}$, $B$, and $C$ show a typical series of tests in normal subjects ( $A$ and $C$ females; $B$ male). The first few single muscle contractions were 10 seconds apart. The first test was made at a stimulation rate of 0.5 per second. Throughout this run there was a gradual increase in the strength of each succeeding contraction, the phenomenon of potentiation. The first, and maximum, contraction during the recovery period which followed this test was equal to the maximum contraction during the test. Following this there was a gradual decrease in the contraction height (loss of potentiation) to the strength (height) which preceded the test.
With increase in the rate of stimulation to 1,2 , and 4 per second the build-up in contraction height occurred at a more rapid rate, and the maximum potentiation was reached long before the end of the $1 \frac{1}{2}$-minute test period. With 1 and 2 per second, and occasionally at 4 per second frequencies, the maximum potentiation was maintained to the end of the test run. In most 4 per second tests the height of contraction fell off near the end of the test. At 8 per second there was usually an early partial fusion of tetanus which occasionally became completely fused. At 16 per second, fusion of tetanus occurred in all of our tests, pain usually limiting the application of stimulus at this rate for periods longer than 3 seconds (Figure 2F).

The first single contraction after the 1 and 2 per second tests usually equalled the height of the maximum contraction attained during the preced- 


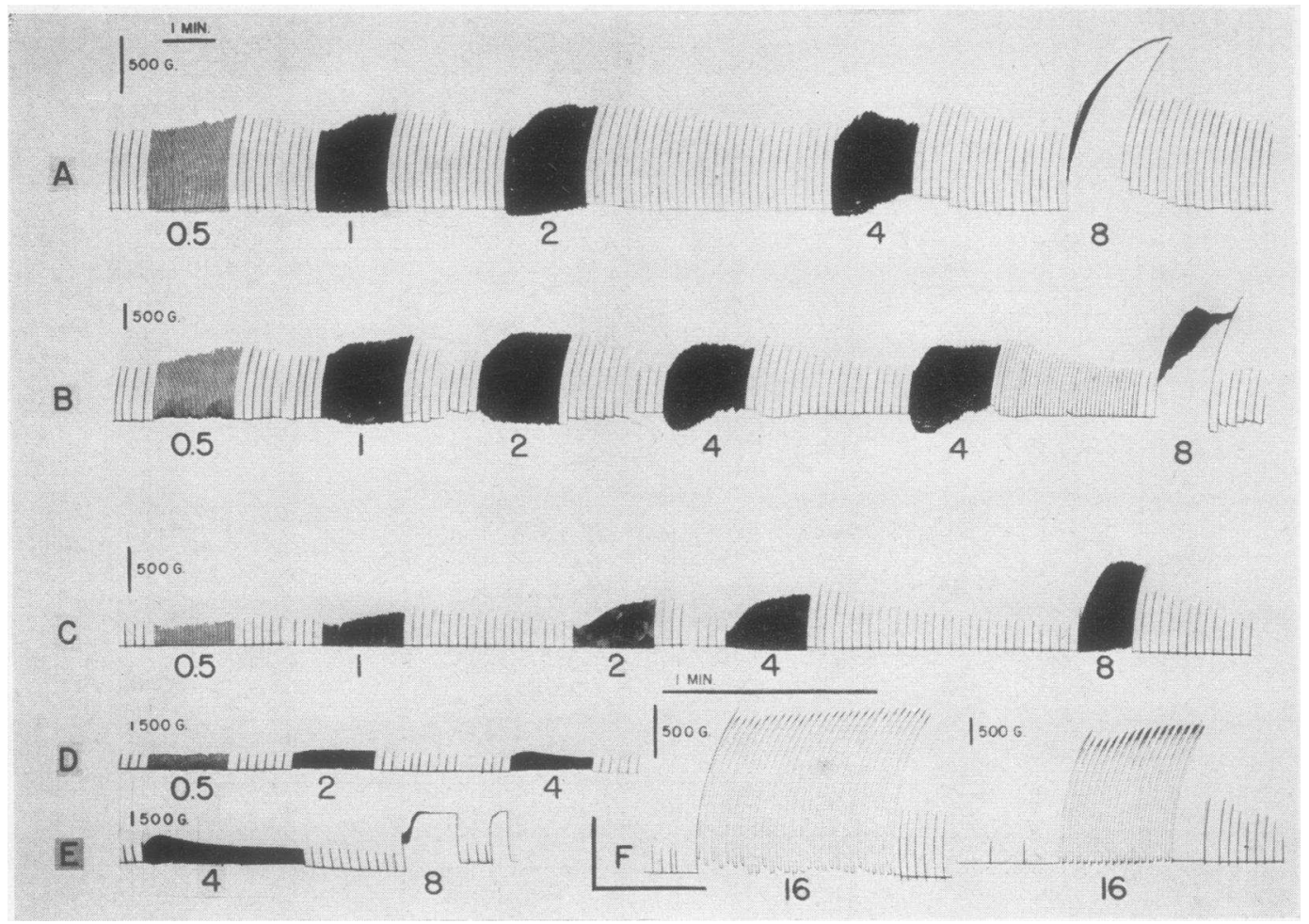

Fig. 2. Myograms of Normat. Subjects

The tension of the myograph is shown in the left upper corner of each record. The number below each record indicates the frequency of stimulation per second. A. Record of a normal woman. B. Record of a normal man. Note the similarity of the two 4 per second tests. C. Record of a normal woman. D. Same subject as in B. Torsion wire myograph with nearly isometric muscle contractions. E. Same subject as B. Isotonic myograph; increased tension. F. Two records at 16 per second frequency. Stimulation for 3 seconds alternating with rest for 3 seconds.

ing test run. At 4 per second this was occasionally true. In most subjects, however, the first one (or few) single contraction after a 4 per second test run was of lower height than the maximum contractions during the preceding test run. The contraction height then usually increased to this maximum before recovery from potentiation began. During the recovery period, the loss of potentiation occurred rapidly at first and then more slowly as the resting contraction height was approached. Recovery from potentiation was slower in males than females. In all subjects the time of recovery, i.e., the restoration of the height of contraction to the baseline level, was inversely proportional to the stimulation speeds or to the degree of potentiation. The potentiation produced by stimulation at a rate of 0.5 per second often was not completely lost during the following recovery period when the contractions occurred every 10 seconds.

In most physically well-trained and non-fatigued subjects a steady increase in the height of contractions was observed during the slow tests. In many subjects, however, early in the 2,4 , and 8 per second tests the height of contractions fell off from the beginning for a short space and was then followed by a secondary rise in the contraction height (Figure 2C). This early dip in the contraction height was most marked at the more rapid frequencies. It became more prominent after repeated test runs, or appeared then for the first time (Figure $3 \mathrm{E}$ ).

\section{Factors altering the normal response.}

One of the chief causes for unsatisfactory myograms was an inability of patients to relax dur- 


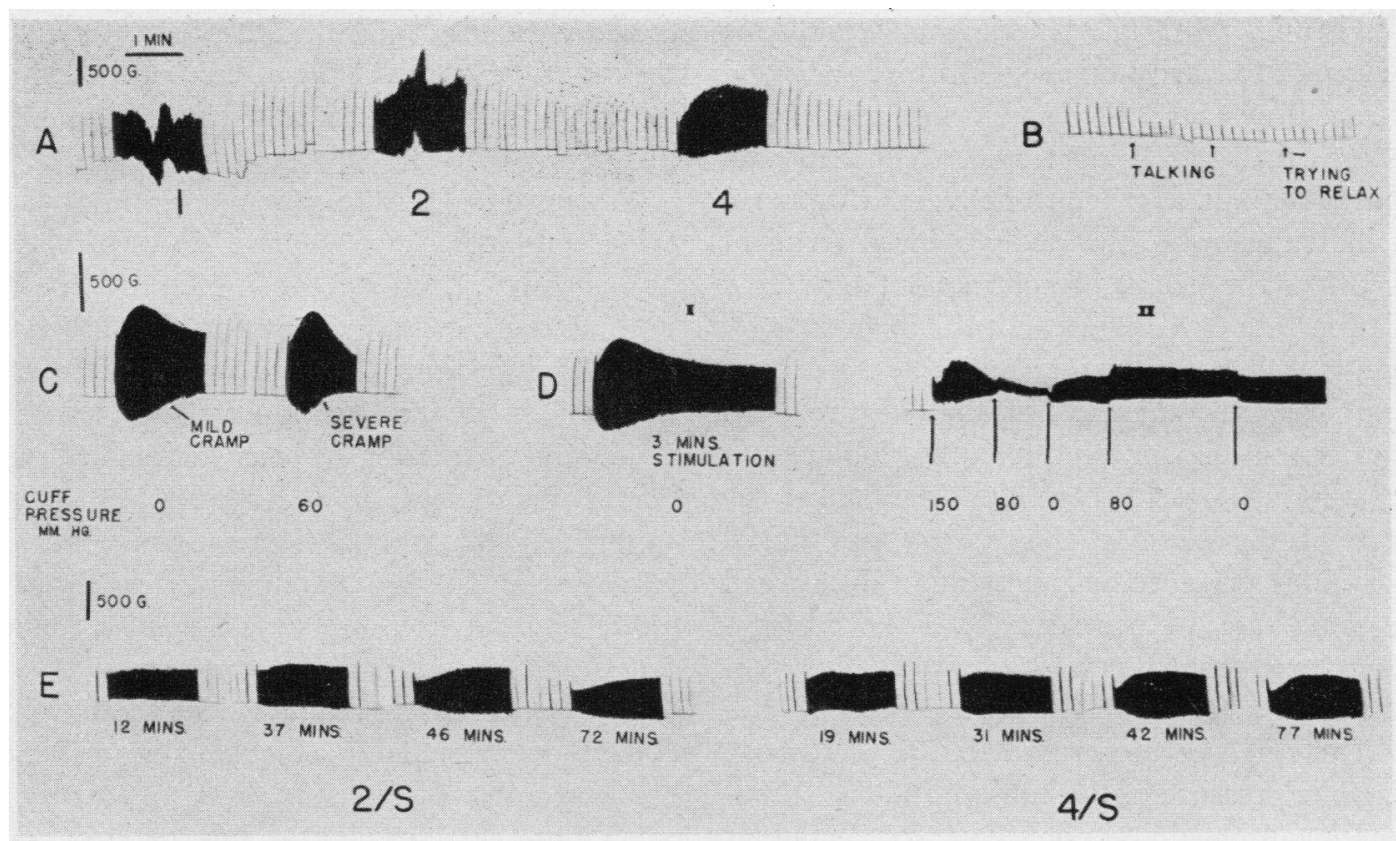

Fig. 3. Myograms on Normal Subjects

Explanation of figure is the same as for Figure 2. (Parts of the myogram were re-inked before being photographed.) A. Myogram of 33-year-old man with severe anxiety state. During the first 2 tests the patient was emotionally upset and almost "in tears." Note that his response is within normal limits. B. Record of a normal but moderately tense young woman during a casual conversation. Tensing of all arm muscles caused a decrease in contraction height. Stimulation rate: 1 per 10 seconds. C. Record showing influence of an inflated pressure cuff above the elbow of the arm being tested. A rapid decline in the height of contraction occurred in association with a severe cramp in the forearm. D. Normal man (same as subject $B$, Figure 2). $D_{1}$, normal curve; 3 minutes of stimulation at a rate of 4 per second. $D_{2}$, influences of a blood pressure cuff inflated to various levels; blood pressure of subject 114 per 74. E. Influence of prolonged testing. During a period of 1 hour and 20 minutes, 12 tests (6 at 2 per second and 6 at 4 per second) were made. Between these tests stimuli were applied every 10 seconds. Note the development of a primary dip after prolonged stimulation.

ing experiment. Figure $3 \mathrm{~A}$ shows the effect of general muscular tension on a myographic record: the subject was in a state of chronic severe anxiety but otherwise well. Note also the effect of mental concentration on the muscle contractions (Figure 3B). This appeared to increase the general muscular tension, particularly of the antagonistic muscles, and resulted in a lessening of the contraction height. This effect sometimes became less marked at stimulation rates of 4 per second or faster, as the subjects were then less able voluntarily to control their contractions. Mild sedation with phenobarbital (60 mgm.) and assurance were of assistance, but never abolished the "emotional tension factor." Significant pain was almost constantly present during stimulation frequencies of 16 per second or faster, and was often present at 8 per second. As a consequence many of these records were of doubtful reliability.

The character of the myogram was influenced some by the tension of the myograph (compare Figure $2 \mathrm{~B}, \mathrm{D}$, and $\mathrm{E}$ ). It was an inconstant observation that increased tension was associated with an increased potentiation. With less than ideal tension the myograph lever overswung. To avoid these difficulties the optimal tension for each subject was chosen with care and was the same during repeated tests.

Pain in the contracting muscles, accompanied by a cold and moist hand, attended the falling off of contraction which occurred toward the end of test runs at 2,4 , and 8 per second stimulations. This pain was identical to that which resulted 
from ischemia. Several experiments were done in an attempt to clarify this relationship. A blood pressure cuff was applied about the upper part of the arm that was being tested. The cuff was inflated to $60 \mathrm{~mm}$. $\mathrm{Hg}$ before delivery of tetanus. In an individual who repeatedly showed terminal falling off of the height of contractions only at a stimulation rate of 4 per second, this phenomenon occurred much more rapidly and was associated with an increased amount of pain (Figure 3C). In another experiment (Figure 3D), following a control test at 4 per second for 3 minutes, the pressure of the blood pressure cuff was raised above systolic pressure and the stimuli discharged at the same rate (4 per second). The contractions weakened rapidly, but returned slowly toward normal after complete release of the pressure. The cuff was then re-inflated to just above the diastolic pressure of the subject and the stimulation was continued at 4 per second for 2 minutes with only slight fall in the contraction height. While the stimulation was continued the cuff pressure was then released and only a barely perceptible increase in the contraction height occurred. To exclude interference of the cuff with muscular contractions, in other experiments localized pressure was applied to the brachial artery; the contraction response was the same as with the cuff.

The roles of general body anoxia and hypoglycemia were investigated. One subject breathed a 10 per cent oxygen- 90 per cent nitrogen mixture until cyanosis was present. During several periods of cyanosis which lasted 10 to 15 minutes, standard tests were done. The responses were identical with those observed under normal conditions. Likewise 2 subjects who were made hypoglycemic by the administration of insulin intravenously (blood sugars reached 27 and $20 \mathrm{mgm}$. per cent, respectively) showed responses no different from those obtained under normal conditions.

\section{Myograms in pathological states.}

(a) Addison's disease: The method of myography described here was developed to aid in the evaluation of the muscular function of patients with Addison's disease being treated with various adrenal cortical hormone preparations. In general, only those who exhibited marked weakness clinically showed significant changes in their muscle curves. Two examples of this will be presented with short abstracts of their clinical histories (1).

Patient H. J., a 55-year-old male, was maintained on large supplementary doses of $\mathrm{NaCl}$ (14 grams daily), from 1939 to 1943 . In 1940 a right orchidectomy was performed for tuberculosis. In 1943 injections of desoxycorticosterone were begun. A tuberculous kidney was removed in 1944, and thereafter he was maintained on pellets. This patient showed a tendency to develop hypertension. Hypoglycemic manifestations occurred only during intercurrent infections. The 17-ketosteroid excretion was $3.8 \mathrm{mgm}$. daily and the B.M.R., -18 per cent.

The patient was maintained in the hospital for 6 days on presumably adequate doses of desoxycorticosterone (1.5 mgm. every other day) and salt. On the third day of this regimen, a myogram (Figure 4A) showed slight potentiation of muscle contractions at $0.5,1$, and 2 per second test runs and a prominent primary dip followed by no potentiation at 4 per second. On the sixth day (Figure 4B) the patient complained of increasing weakness. His myograms exhibited no potentiation of muscle contractions at 0.5 and 1 per second, and only slight potentiation at 2 and 4 per second rates. A primary dip was present at both these speeds. After 3 days of treatment with desoxycorticosterone (1 mgm. daily) and $15 \mathrm{mgm}$. of corticosterone daily, the patient felt much stronger and exhibited improved muscle function. There was increased contraction height and normal muscular potentiation at $0.5,1,2$, and 4 per second tests with considerable lessening of the primary dip at 2 and 4 per second (Figure $4 \mathrm{C}$ ).

Patient M. N. was maintained on pellets of desoxycorticosterone acetate. She had a tendency for edema to develop when given more than 2 mgm. of hormone daily. The patient also had frequent spontaneous bouts of hypoglycemia which were prevented by daily 3-cc. injections of Upjohn's adrenal extract in oil. This latter treatment greatly improved her muscular strength. It was not possible for her to maintain her weight and strength when receiving only $3 \mathrm{cc}$. of LipoAdrenal Cortex daily. The 17-ketosteroid excretion was 0 , and B.M.R., -18 per cent.

She had been receiving Upjohn's Lipo-Adrenal 


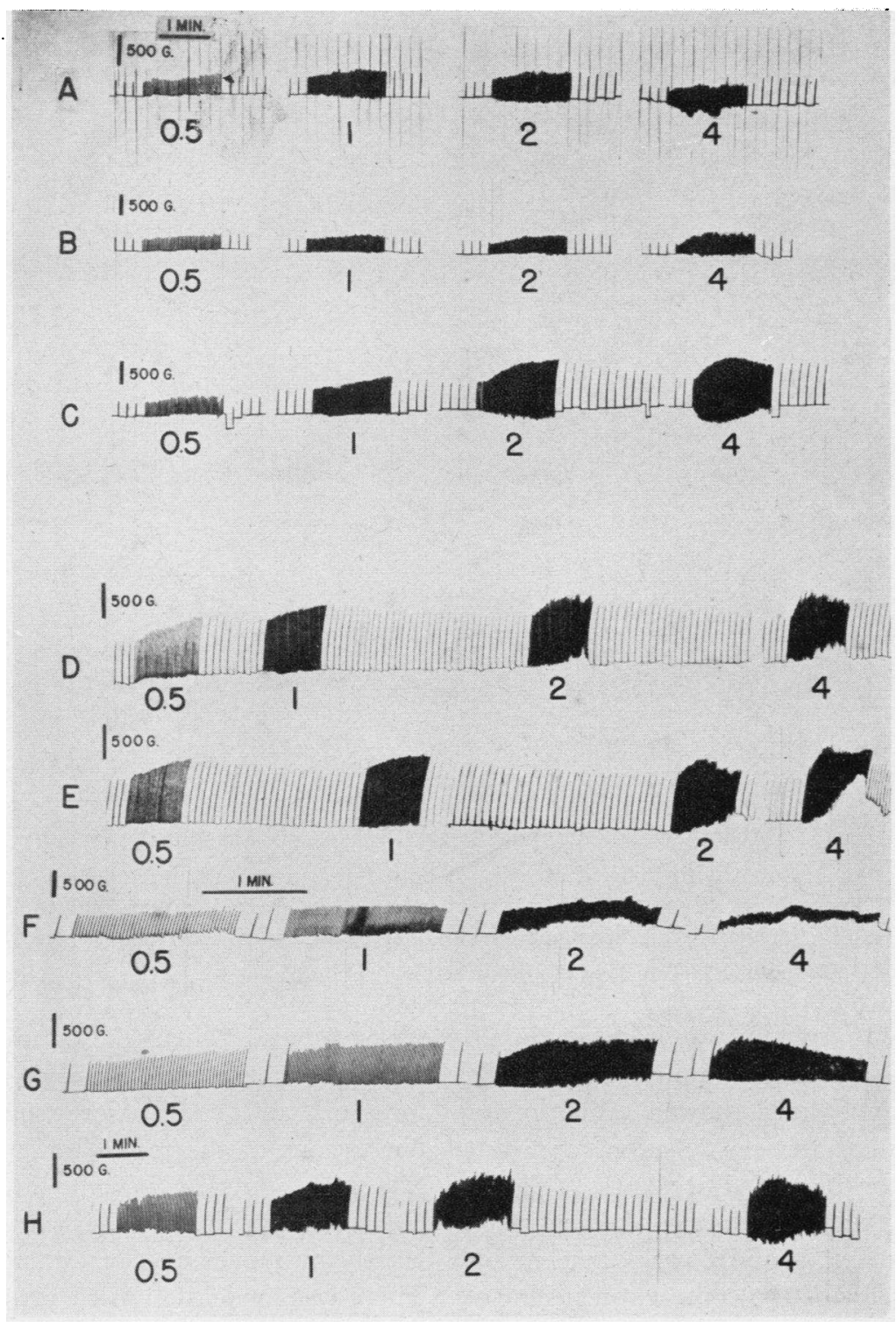

Fig. 4. Myograms on Patients with Addison's Disease

Explanation of figures is the same as for Figure 2. A. $H$. J. Therapy: desoxycorticosterone plus salt. B. $H$. $J$. Three days later; same therapy. C. H.J. Compound $\mathrm{A}$ added to above treatment for 3 days. D. $M . N$. Therapy: Upjohn's extract and eschatin. E. $M$. $N$. Patient given only desoxycorticosterone for 3 days. F. $M . N$. Six hours later, after receiving $30 \mathrm{mgm}$. Compound A in oil. G. $M . N$. Two days later, after combined desoxycorticosterone and Compound $\mathrm{A}$ in oil therapy. H. M. N. Three days on combined treatment.

Cortex for several days when the myographic curves shown in Figure 4D (regarded as normal) were taken. She was then placed on $1 \mathrm{mgm}$. of desoxycorticosterone daily for 3 days, the Lipo-
Adrenal Cortex being discontinued. On this regimen she became weak and easily exhausted. A myogram (Figure 4E) showed a decrease of the contraction height near the middle of the 2 


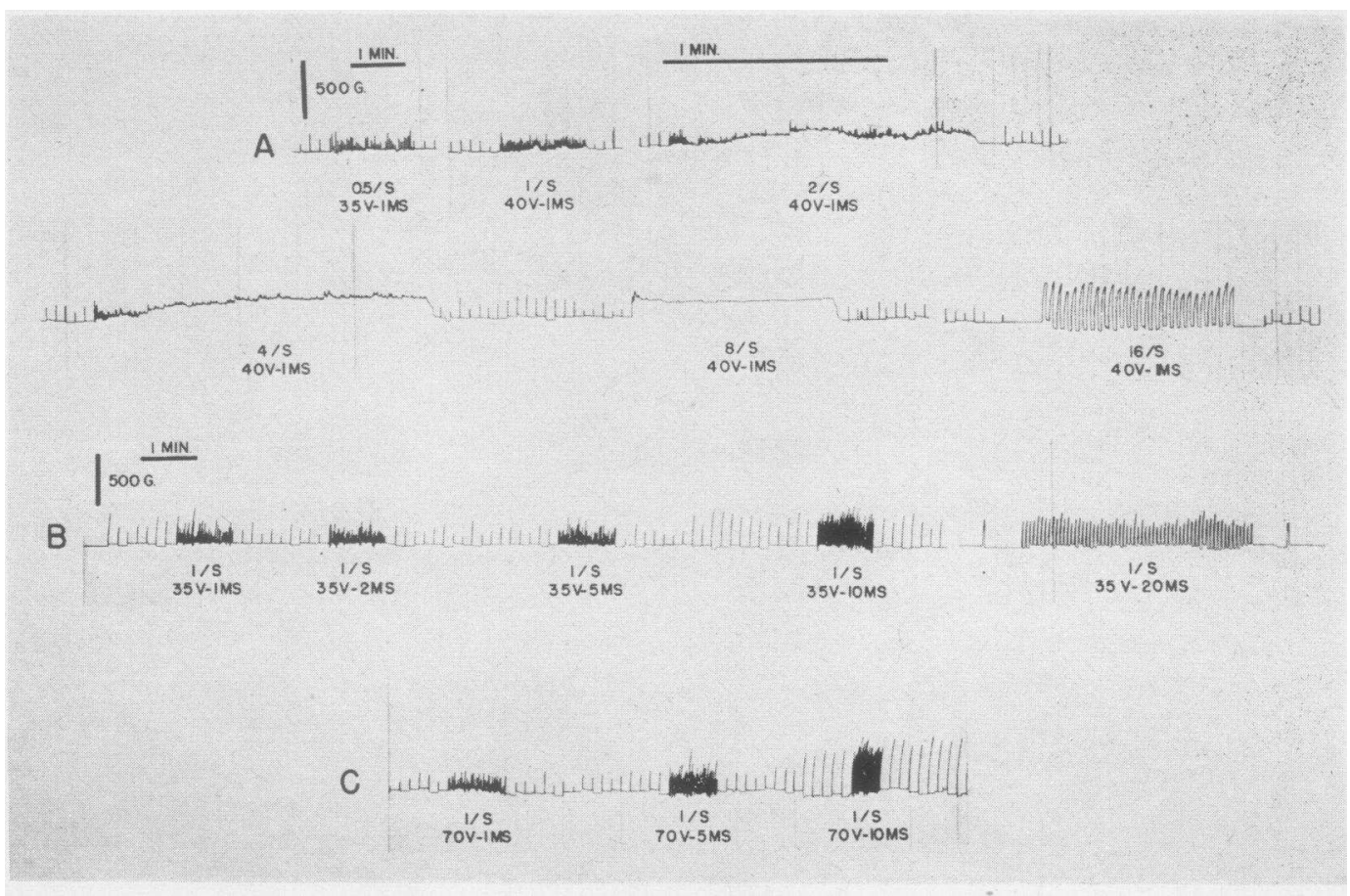

Fig. 5. Myogran on a Patient with Progressive Muscular Atrophy

A. A 43-year-old woman with marked atrophy of both forearms. Note irregularity of muscular contractions. B. Same subject. Increasing duration of stimulation from 1 millisecond to 20 milliseconds increases height of contraction but does not eliminate irregularity of the responses. C. Same subject. Electrode applied over the flexor carpi ulnaris muscle.

per second test. In spite of an injection of 20 mgm. corticosterone given intramuscularly in oil, a repeat test 6 hours later showed even greater evidence of impaired muscle function, and this correlated with her increased weakness (Figure $4 \mathrm{~F}$ ). There was a complete absence of potentiation during test runs at $0.5,1$, and 2 per second in addition to a falling off of the contraction height at 2 per second. Three days later after receiving 1 $\mathrm{mgm}$. of desoxycorticosterone and $30 \mathrm{mgm}$. corticosterone daily for 2 days, the patient felt stronger (see Figure 4G), and 3 days later very much stronger (Figure $4 \mathrm{H}$ ). Note the increased height of single muscle contractions, and improved muscle potentiation.

(b) Progressive muscular atrophy: Two patients with this condition were studied. In 1 instance the atrophy in the upper extremities was mild, in the second it was severe. This latter patient had noticed the onset of weakness, fibrillations, and atrophy in the hands about 18 months earlier. The condition had been steadily pro- gressive, and when the studies reported here were done, the atrophy and weakness of both forearms and hands were severe and frequent fibrillations of the tested muscles were observed. She could grasp a pencil with either hand and hold it for writing, but writing was accomplished largely by movements of the shoulder and elbow. There was moderate muscle atrophy and weakness of the shoulder girdles, but no weakness or atrophy of the trunk or lower extremities. Signs of pyramidal tract disease were absent.

This patient's myograms are shown in Figure 5. Figure 5A shows her response to a standard test plus 8 and 16 per second tests. The outstanding feature of this test in addition to evident weakness is the irregular height of the contractions, regardless of the stimulation speed. In Figure $5 \mathrm{~B}$ the duration of each electrical stimulation is increased from 1 to 20 milliseconds. In spite of the general increase in the contraction height, the variation in individual contractions persisted. The single twitches in the 20 -milli- 
second series are notched at their peaks due to repetition of the muscle twitch. In other experiments the stimulation current was increased to 70 volts with no significant difference in the character of the muscular contractions. In Figure 5C the stimulating electrode was placed on the skin over the flexor carpi ulnaris muscle. The character of the contractions was the same as before. An additional feature in this case was a tendency for tetanus to be fused at stimulation speeds of 4 per second. At 8 per second functional fusion was produced (see Figure 5A).

The myograms of the patient with less marked atrophy showed lesser, but similar irregularities of contraction, during testing. In this patient there was no tendency to fusion of tetanus at the stimulation speed of 4 per second.

\section{DISCUSSION}

Two alterations in the myograms of normal subjects might have been considered evidence of "fatigue" and certainly indicated an altered state of muscle function. The first was a prominent dip in the myogram immediately after the beginning of a 2 or 4 per second test which was then followed by the usual potentiation of muscle contractions. This change usually became prominent, or in some subjects appeared for the first time, after repeated stimulation of the ulnar nerve over periods of an hour or longer. In correlation with this, von Euler and Swank (2) observed this phenomenon to be well developed in cats and pigeons toward the end of long experiments. These observations suggest that this change in the myogram is a manifestation of an alteration in the state of the muscle, not quickly reversible to normal.

The second change in the myogram which correlated with "fatigue" was a falling off of muscle contractions in the last 30 to 45 seconds of a $1 \frac{1 / 2-}{2}$ minute test at 2 to 4 per second. This was also produced by ischemia of the contracting muscles. The pain in both instances was identical and it is felt that the mechanism in both instances was in large part ischemia; in the former due to the contracting muscles or to vasoconstriction incident to slow stimulation or apprehension, and in the latter to the blood pressure cuff.

The early dip in the myogram occurred in exaggerated form in Addison's disease, and it was usually followed by a less than normal potentiation. Adequate treatment of the Addison's disease was accompanied by reversal of these changes toward normal. Like the normals, all patients with Addison's disease exhibited a falling off of the height of contraction during the latter part of a 4 per second test, and unlike the normals most of them showed this same phenomenon during 2 per second tests.

A third alteration in the myogram was observed only in patients with Addison's disease and in 2 others with thyrotoxic myopathy. It consisted of an absence of potentiation of the muscular contractions normally present during repeated stimulation. This was accompanied by severe and generalized weakness. This would appear to be a manifestation of the abnormal metabolic state present in the muscles of patients with Addison's disease since normal muscle potentiation was observed in these same muscles after treatment of the underlying deficiency. It should not be overlooked that there was a delay of several days at least between the giving of adequate treatmient for the Addison's disease and restoration of a normal subjective feeling of strength and a normal muscle myogram.

The method of myography described herein detected and recorded alterations in muscle function in severe Addison's disease. In milder Addison's disease, even though subjective weakness and fatigability were complained of, the myograms were usually normal. In general it can be stated that the patient's subjective feeling of weakness or fatigue was probably a more sensitive indication of the severity of the Addison's disease than the myogram. It is of interest that neither hypoxemia nor hypoglycemia of a severe grade (yet neither severe enough to produce unconsciousness) were attended by any of the manifestations of altered muscle function described in this paper.

High frequency stimulation, as used by Odom et al. (3), was not employed because of the pain which it produced. It was felt by these workers that they were inducing fatigue at the neuromuscular junction. The rates of stimulation used in our experiments, in all probability, did not produce fatigue at the neuromuscular junction, but demonstrated an alteration primarily in muscle function. The work of del Pozo on cats lends support to this (4). With stimulation frequencies 
of 30 per second and greater, a type of fatigue resulted which was quickly reversible to normal. This was thought to be due to transmission fatigue. Following stimulation with frequencies of less than 20 per second, the rate of recovery was slow. This was considered due to fatigue in the muscle.

The variability of the contraction height in patients with primary muscular atrophy suggests a remarkable spontaneous alteration of the sensitivity of the neuromuscular apparatus to electrical stimulation. It is unlikely that the failure of each stimulation to elicit uniform responses was due to subthreshold stimulation, since very high voltages were tried without altering this character of the myogram. The variation may be explained, however, by the observation of Bourguignon (5) that the chronaxie of involved muscles in patients with amyotrophic lateral sclerosis is at first reduced and later increased. Whereas the more irritable units respond to each electrical stimulation, the less irritable ones frequently fail to respond. The peripheral nerve and its cell body as well appear also to be abnormally irritable in this disease since novocainization of peripheral nerves progressively nearer to the muscles which they innervate diminishes progressively the number of fasciculations in these same muscles, without completely abolishing them until the novocaine is injected into the fasciculating muscle (Swank and Price, [6]). Preceding (Grund, [7], Shelden and Woltman, [8]) and more recent work (Odom, Russel, and McEachern,[3], Forster, Borkowski, and Alpers, [9]), showing that fibrillations still occur in muscles deprived of their motor innervation by novocainization or surgical incision, confirms the observation that the stimuli giving rise to muscle fasciculations can arise in the distal part of the peripheral nerve, but does not establish this region as the only possible point for their origin.

A possible relationship exists between the myograms, and the predominating sizes of motor nerve fibers in normals and in patients with amyotrophic lateral sclerosis. It has been shown that normal ventral spinal roots contain 2 general classes of nerve fibers, small and large (Kiss and von Mihalik, |10|. Eccles and Sherrington, [11]. Häggqvist, $|12|$, and Swensson, |13]). In amyotrophic lateral sclerosis the large fibers degenerate first. leaving the small fibers relatively intact (Wohlfart and Swank, [1+]). In patients with severe muscle atrophy very few large fibers may be left. If the small and large motor nerve fibers have different functions then one wonders which part of the myogram from the patient with progressive muscular atrophy was due to the few remaining large fibers, and which was due to the large number of intact small fibers. Marked weakness was obvious. The answers to other questions are not clear, however. Was the remaining power due to small fibers or to the few remaining large fibers? Was the variation in strength of contraction related to large or small fiber function? Was the tendency to fusion of tetanus at the stimulation frequency of 4 per second due to a predominance of small fibers in the motor nerves?

It is of some interest that a tendency to fusion of tetanus was observed in most normal patients at stimulation frequencies of 8 per second, and in some instances (Figure 2A) functional fusion seemed to have developed by the end of the test. When stimulated at 16 per second a sustained fusion of tetanus was observed in all patients. ${ }^{4}$

\section{SUMMARY AND CONCLUSIONS}

To record alterations in muscle function in humans, a method of myography commonly used in animals has been employed. In normal subjects slight changes in the myogram were detected which correlated with fatigue. In patients with severe Addison's disease and in others with thyrotoxic myopathy these changes were exaggerated. and an absence of the muscle potentiation normally present during repeated stimulation was observed. These alterations were restored to normal in patients with Addison's disease by adequate treatment. In other patients with progressive muscular atrophy a marked variation in the height of muscle contraction was observed. The factors which normally influence the character of the myogram are described. Pain, due to electrical stimulation of the ulnar nerve, is the most important of these factors, and causes a number of unsatisfactory myograms.

\footnotetext{
4 Beginning fusion of tetanus at stimulation frequencies of less than 20 per second is illustrated several times in a paper by Dr. Derek Denny-Brown entitled "Interpretation of the Electromyogram" which is now in press with the Archives of Neurology and Psychiatry.
} 


\section{BIBLIOGRAPHY}

1. Forsham, P. H., Thorn, G. W., Bergner, G. E., and Emerson, K., Jr., Metabolic changes induced by synthetic 11-dehydrocorticosterone acetate. Am. J. of Med., 1946, 1, 105.

2. Von Euler, U. S., and Swank, R. L., Tension changes during tetanus in mammalian and avian muscle. Acta Phys. Scandinav., 1940, 1, 203.

3. Odom, G., Russel, C. K., and McEachern, D., Studies of neuromuscular disorders; the myogram, blood cholinesterase and effect of prostigmine in myasthenia gravis and progressive muscular atrophy. Brain, 1943, 66, 1.

4. Del Pozo, E. C., Transmission fatigue and contraction fatigue. Am. J. Physiol., 1942, 135, 763.

5. Bourguignon, G., La chronaxie dans la sclerose laterale amyotrophique. Rev. Neurol., 1925, 1, 808.

6. Swank, R. L., and Price, J. C., Fascicular muscle twitchings in amyotrophic lateral sclerosis; their origin. Arch. Neurol. \& Psychiat., 1943, 49, 22.

7. Grund, G., Ueber die Entstehung der fibrillaren Muskelzuckungen bei spinalen Amyotrophien. Deutsche Ztschr. f. Nervenh., 1938, 145, 99.

8. Shelden, C. H., and Woltman, H. W., Origin of fibrillary twitchings. Proc. Staff Meet., Mayo Clin., 1940, 15, 646.

9. Forster, F. M., Borkowski, W., Jr., and Alpers, B. J., Effects of denervation on fasciculations in human muscles. Relation of fibrillations to fasciculations. Arch. Neurol. \& Psychiat., 1946, 56, 276.

10. Kiss, F., and von Mihálik, P., Ueber die Zusammensetrung der peripherischen Nerven und den Zusammenhang zwischen Morphologie und Funktion der peripherischen Nervenfasern. Ztschr. $f$. d. ges. Anat. (Abt. 1), 1928, 88, 112.

11. Eccles, J. C., and Sherrington, C. S., Numbers and contraction-values of individual motor-units examined in some muscles of limb. Proc. Roy. Soc., London, 1930, s. B 106, 326.

12. Häggqvist, G., Zur Kenntnis einer doppelten cerebrospinalen Innervation der Skeletmuskeln. Ztschr. f. mikr.-anat. Forsch., 1938, 43, 491.

13. Swensson, $\AA$., Ueber die Kaliberverhältnisse in den vorderen Rückenmarkswurzeln beim Menschen. Ztschr. f. mikr.-anat. Forsch., 1938, 44, 187.

14. Wohlfart, G., and Swank, R. L., Pathology of amyotrophic lateral sclerosis. Fiber analysis of the ventral roots and pyramidal tracts of the spinal cord. Arch. Neurol. \& Psychiat., 1941, 46, 783. 